\title{
Transdisciplinary Modification of Competencies of the Future Physical Culture Teacher
}

\author{
Zhabakov V.E. \\ Theory and Methodology of Physical Culture and Sport \\ Department \\ South-Ural State Humanitarian-Pedagogical University \\ Chelyabinsk, Russia
}

\author{
Zhabakova T.V. \\ Pedagogics and Psychology Department \\ South-Ural State Humanitarian-Pedagogical University \\ Chelyabinsk, Russia
}

\author{
Vorozheykina A. V. \\ Pedagogics and Psychology Department \\ South -Ural State Humanitarian-Pedagogical University \\ Chelyabinsk, Russia
}

\begin{abstract}
The article substantiates the urgency of competencies transdisciplinary modification among the future physical culture teachers. As a "nucleus" of transdisciplinary, which connects competencies of educational standard 44.03.05 into a single conceptual context, we chose subjectivity. The main research methods are the following: scientific literature analysis, connected with the problem of transdisciplinarity, diagnostic methods, which include content-analysis of competencies, modified V.I. Baydenko questionnaire. For statistical results handling we used software «SPSS v 17.0», Fisher's ratio test $\varphi^{*}$. As a result of the empirical study we revealed the features of "subjectivity" in general professional and universal competencies. The authors presented the characteristic of subjectivity indicators, described the blocks of transdisciplinary modification of competencies. The authors underline that transdisciplinary competencies introduction into the teaching process of the future physical culture teachers conditioned statistically significant changes in the competence, priority, tension and modified competencies support in the notions of the future physical culture teachers of the experimental groups.
\end{abstract}

Keywords - transdisciplinarity; the future physical culture teacher's competencies.

\section{INTRODUCTION}

Central tendencies of students' high competence level provision in the sphere of physical culture and sport become disciplines "combination" in terms of general methodological ideology of transdisciplinary educational environment formation. At the same time orientation towards transdisciplinarity becomes special methodological "ideology" [9] in training pedagogical University students, as the future physical culture teacher training demands not only earlier dissociated parts of training (theoretical and practical) integration [6] into a system education, but also a new "metaknowledge" construction [5].

\section{LITERATURE REVIEW}

The problem of studying educational environment of higher educational establishments is reflected in scientific works of V.S. Mokiya, M.S. Mokiya [7], N.Y. Didenko, L.P. Kiyashchenko [4], E.G. Grebenshchikova, E.N. Knyazeva [5], V.N. Porus [9] and others. In the opinion of M.S. Mokiya [7], transdisciplinarity models of spatial, temporal and informational unit form the base of transdisciplinarity methodology, which provides coordination of disciplinary knowledge on the basis of general axiomatic approach. V.N. Porus [9] mentions that transdisciplinarity gives an opportunity of a new scientific discourse in philosophy of science and philosophy of culture. The opportunities and perspectives of transdisciplinary approaches realization in education study L.P. Kiyashchenko, E.G. Grebenshchikova, who consider the main theory of transdisciplinarity, in a new educational paradigm, methodology of science transformation and new aspects of innovatics development [4]. E.N. Knyazeva, describing the main directions of modern transdisciplinary research works (complexity theory, futureoriented research, cognitive science) underlines, that transdisciplinary studies define the image of modern science [5]. Thus, transdisciplinarity in modern science is understood as a new direction in philosophy of science development, directed toward the ways of modern scientific research works transformation.

\section{RESEARCH METHODOLOGY}

Empiric research work was held since January till May, 2019 on the basis of physical culture and sport theory and methodology department of physical culture and sport Higher school at South-Ural state humanitarian-pedagogical university in Chelyabinsk. 120 people at the age of 18-22 took part in the research.

Empiric study was realized in two stages. At the first stage, using the method of content-analysis, we studied universal and general professional competencies of the future 
physical culture teachers. In case of transdisciplinary modification of physical culture teacher's competencies there is the process of the mentioned competencies succession and content complication. That is why it is necessary to define the context, which would preserve the unity of educational environment. This context, "nucleus of transdisciplinary", in our opinion, can be subjectivity. That is why as the categories for content-analysis we chose the directions of "subjective experience" formation. At the second stage of the research we modified general professional and universal competencies, using the potential of transdisciplinary disciplines combination. At the third stage of the research in order to define subjective importance of transdisciplinary competencies modified V.I. Baydenko questionnaire was used [1]. For statistical results handling we used «SPSS v 17.0» software, descriptive statistics and Fisher's ratio test $\varphi^{*}$.

\section{RESULTS}

Content-analysis of universal and general professional competencies of $3++$ standard in "Pedagogical education" direction gives an opportunity to make conclusion about subjectivity features presence in competencies.

The first indicator of subjectivity is contextual realization of subject-subjective personality relations in competencies formulation. For example, in universal competence-1 (UC-1) (able to realize search, critical analysis and synthesis of information, use system approach for the objectives solution), UC-2 (able to define objectives in terms of the set aim and choose optimal ways of their solution, taking into account existing juridical norms, resources and restrictions), UC-6 (able to manage own time, create and realize the trajectory of self-development on the basis of principles of education during the whole life), UC-7 (able to support necessary level of physical readiness for high-grade social and professional activity provision) subject-subjective relations are demonstrated in a form of exteriorized subjectivity and are directed toward interaction formation with life situation in terms professional activity. For example, UC-1 (able to realize search, critical analysis and synthesis of information, use system approach for the objectives solution) should be considered as system forming factor of professionalism, which provides professional-personal experience stereotypes overcoming and problem situations solution, which appear during the process of professional-pedagogical objectives solution on the basis of exteriorized subjectivity.

Potential of subjectivity on the basis of subjectsubjective orientations in subjective form of inner picture of life activity (interiorized subjectivity) and objective form of behavioral strategies choice (exteriorized subjectivity) [3] is mainly concentrated in the context of general professional competencies. The following general professional competencies are directed toward interiorized subjectivity formation: GPC-2 (able to take part in the main and additional educational programs creation, create their separate components, including those with informationalcommunicative technologies use), GPC-4 (able to realize spiritual-moral upbringing of students on the basis of basic national values), GPC-8 (able to realize pedagogical activity on the basis of special scientific knowledge).
Exteriorized subjectivity is formed in the following competencies: GPC-3 (able to organize mutual and individual educational and upbringing activity of students, including students with special educational needs, in accordance with the demands of federal state standards), GPC-6 (able to use psychological-pedagogical technologies in professional activity, necessary for education individualization, development, upbringing, including students with special educational needs).

Thus, competencies context analysis of $3++$ standard in "Pedagogical education" training direction helps to come to the conclusion that the context of competencies, both universal and general-professional ones, has the system of inner and outer conditions of behavior formation and the activity of the future teachers, which influence the peculiarities of perception, understanding and the definite situation of professional pedagogical activity transformation by the subject. This activity conditions the essence and meaning of this situation as professionally important.

Transdisciplinary modification of competencies of educational standard 3++ in 44.03.05."Pedagogical education" direction of training (with two profiles of training) was realized in such modules as subjective-content, methodical. Transdisciplinary modification was held both for competencies of educational and variable part of disciplines.

The first block of transdisciplinary modification of competencies we called conceptual. The disciplines of this block are the following: history of physical culture, the basis of scientific-methodical activity, pedagogical physical culturesports development, sportsmanship improvement, sports management, pedagogics of physical culture, psychology of physical culture. They are combined into general transdisciplinary conceptual position, where the priority is given to objective and inter subjective scientific knowledge. This kind of conceptual position would help to understand professional problems and offer the ways of professional objectives solution in terms of the corresponding transdisciplinary world view. Subjectivity of the future physical culture teacher is connected with his ability to turn own life, education, process of professional formation into the subject of practical transformation and corporality improvement as the base of personality's physical culture. Subjective-professional potential of the formed corporality of the future physical culture teacher accumulates into his forming professional abilities (competencies) to practical realization in educational-upbringing process at a higher educational establishment individual trajectories and programs of personal physical culture and sports self-improvement; their necessary correction realization; self-analysis of educationalprofessional and life achievements; the role of professionally and subjectively-oriented competencies increase. That is why the second block we called subjectively oriented corporality.

In the second block transdisciplinary modification of competencies was realized during practical-oriented disciplines, such as bodybuilding and fitness, winter kinds of sport, summer kinds of sport, new kinds of physical upbringing and sport, outdoor games, difficult-coordinating kinds of sport, games, junior sport, professional sport, sports 
training in games, sports training in cyclic and acyclic kinds of sport. Logically disciplines are combined by corporality formation as an epiphenomenon of human being's life. While mastering practice-oriented disciplines corporality is connected with the definite situations, in which the future physical culture teacher studied himself a s a body, and in this case corporality becomes an objective, placed into modified competencies. For our research work it is important that the process of subjectivity formation among the future physical culture teachers is under the influence of outer (reaction to professional initiation, to getting acquainted with the conditions of professional activity, specificity of professional environment, labor market, methods of aims achievement in professional formation on the way of an individual pedagogical trajectory) and inner conditions of life and cognition subject's activity [3]. At the same time, the mechanism of its "counter activity", which has a great notion forming influence on any educational effects, is anticipation and reflexion processes unity. These factors, on the one hand, form social-educational context, on the other hand, provide the specificity of the demonstrated activity during the disciplines study of the third methodical block. Thus, modified competencies should be directed toward subjectivity formation as processuality realization of own development and professional self-determination.

Using modified V.I. Baydenko questionnaire [1] we studied the respondents in order to test the concept, priority, tension and modified competencies support in the notions of the future physical culture teachers. The results of data handling with the help of mathematical statistics show, that statistically valid differences, in terms of error $(\rho \leq 0,01)$ were revealed according to competencies "support" criterion $\left(\varphi^{*}\right.$ emp $=5,1$ in case $\varphi^{*}{ }_{\text {cr }}=1,64(\rho \leq 0,05)$ and 2,31 $\left.(\rho \leq 0,01)\right)$. It means that modified competencies are acknowledged by the respondents important and available for achievement and the process of competencies formation becomes "personally gained".

\section{DISCUSSION}

In our research work the notion "transdisciplinarity" is considered as different research forms and methods integration, including special techniques of scientific cognition, in order to solve scientific problems. This notion means modification as the process of transformation, change of something with new features gaining. During transdisciplinary modification of competencies among the future physical culture teachers there is the process of continuity estimation and logic essence and content of competencies complication. The "nucleus" of transdisciplinary is subjectivity. In this case the level of educational activity formation (the ability of a future physical culture teacher to set and understand educational object, the level of motivation formation, aim setting, control and estimation) can be the base for the process determination of transforming competencies formation into the form of subjectivity, as a new peculiarity of personality of a future physical culture teacher (subject of activity and subject of relations with people around).

\section{CONCLUSION}

Thus, transdisciplinary modification of competencies is a process, which provides cognitive dialogue development in the system of higher education between the definite and indefinite, separable and inseparable, logic and metalogic, set in the competencies of educational standard. Regardless of simplicity of the disciplinary approach and its relative readiness during competencies formation in future physical culture teaching, this approach doesn't give an opportunity to compare fully universal and general professional competencies with the system of quality control of education in the sphere of physical culture. In transdisciplinary approach unity and inner organization are one of the main features of the system.

\section{References}

[1] V.I. Baydenko The content of competencies revelation among higher educational establishments graduates as a necessary stage of new generation State Educational Standard of Higher Education projection: methodical manual. Moscow: Research center of quality problems of specialists training. 2006, 72.

[2] V.E.Zhabakov, T.V. Zhabakova, V.G. Makarenko, G.P. Konyakhina Transdisciplinary approach to educational-training process organization. Human being. Sport. Medicine. 2018, vol. 18, pp. 98-103.

[3] V.E. Zhabakov, A.M. Kuzmin The quality control of training future physical culture teachers in transdisciplinary educational environment: monograph; Ministry of science and higher education of the Russian Federation, South-Ural State Humanitarian-Pedagogical University. Chelyabinsk: South-Ural scientific center RAE. 2019, 184.

[4] L.P. Kiyashchenko Cognitive innovation in terms of philosophy of transdisciplinarity. Knowledge. Understanding. Skill. 2012; №2: 29-32.

[5] E.N. Knyazeva Transdisciplinary strategies of the research. TSPU Bulletin. 2011, 10(112), pp. 193-201

[6] L.V. Lvov,O.V. Perevozova Trabsdisciplinary educational-methodical complex of organizational-managerial competence formation: manual. Chelyabinsk: Publishing house RBIM. 2011, 218.

[7] V.S. Mokiy Methodology of transdisciplinarity -4. Nalchik: ANOITT. $2011,112$.

[8] E.A. Solodova, P.P. Efimov Transdisciplinarity is a modern pedagogical technology of knowledge integration. Integration of education. 2014, 2(75), pp. 20-24.

[9] Transdisciplinarity in philosophy and science: approaches, проproblems, prospects. Under edition of V.A. Bazhanov, R.R. Shtolts. Moscow: Navigator. 2015, 564.

[10]Alexsandr S. Kuznetsov. Russian Professor's meeting. Russian Journal of Physical Education and Sport. 2019, 14(1), pp. 17-22. DOI: 10.14526/2070-4798-2019-14-1-18-24

[11] Transdisciplinarity: Recreating Integrated Knowledge. Editer by Margaret ASomervill\& David J Rapport. 271 pages. Published in 2000 by EOLSS Publishers Co. Ltd. Oxford, UK. 